G. Hasenfuss

L.S. Maier

\section{Mechanism of action of the new anti-ischemia drug ranolazine}

Abstract Myocardial ischemia is associated with reduced ATP fluxes and decreased energy supply resulting in disturbances of intracellular ion homeostasis in cardiac myocytes. In the recent years, increased persistent (late) sodium current was suggested to contribute to disturbed ion homeostasis by elevating intracellular sodium concentration with subsequent elevation of intracellular calcium. The new anti-ischemia drug ranolazine, a specific inhibitor of late sodium current, reduces sodium overload and hence ameliorates disturbed ion homeostasis. This is associated with symptomatic improvement of angina in patients. Moreover, ranolazine was shown to exhibit anti-arrhythmic effects. In the present article, we review the relevant pathophysiological concepts for the role of late sodium inhibition and summarize the most recent data from basic as well as clinical studies.

G. Hasenfuss $(\varangle) \cdot$ L.S. Maie

Dept. of Cardiology and Pneumology

Heart Center Göttingen

Robert-Koch-Straße 40

37075 Goettingen, Germany

E-Mail: hasenfus@med.uni-goettingen.de
Key words angina - ischemia - sodium current - calcium overload

\section{Current therapeutic strategies}

According to the 2006 guidelines of the European Society of Cardiology [16], therapeutic goals of medical treatment of coronary heart disease can be partitioned into (1) immediate short-term relieve, (2) treatment aimed at relieve of symptoms, and (3) treatment aimed at improving prognosis. Interestingly, there is no overlap between drugs that improve prognosis and drugs that relieve symptoms with the exception of $\beta$-blockers after myocardial infarction. This suggests that ischemia which causes symptoms may not be a major mechanism relevant to prognosis, whereas mechanisms which influence thrombocyte function and anti-inflammatory or cytokine-neurohumoral actions may be beneficial for survival.

Current strategies of drug-induced relieve of symptoms aim to improve the imbalance between oxygen supply of the heart and oxygen demand which is relevant to myocardial ischemia and angina pectoris [16]. All agents in this category: $\beta$-blockers, calcium channel antagonists, nitrates, K-channel openers, and sinus node inhibitors reduce myocardial oxygen demand. This occurs either by direct myocardial effects or indirectly by complex effects on hemodynamic determinants [13]. Calcium channel antagonists, nitrates, and K-channel openers in<smiles>COc1ccccc1OCC(O)CN1CCN(CC(=O)Nc2c(C)cccc2C)CC1</smiles>

Fig. 1 Ranolazine, structure 
Fig. 2 Scheme for the pathophysiology of myocardial ischemia and the role of late $I_{\mathrm{Na}}$ inhibition with ranolazine

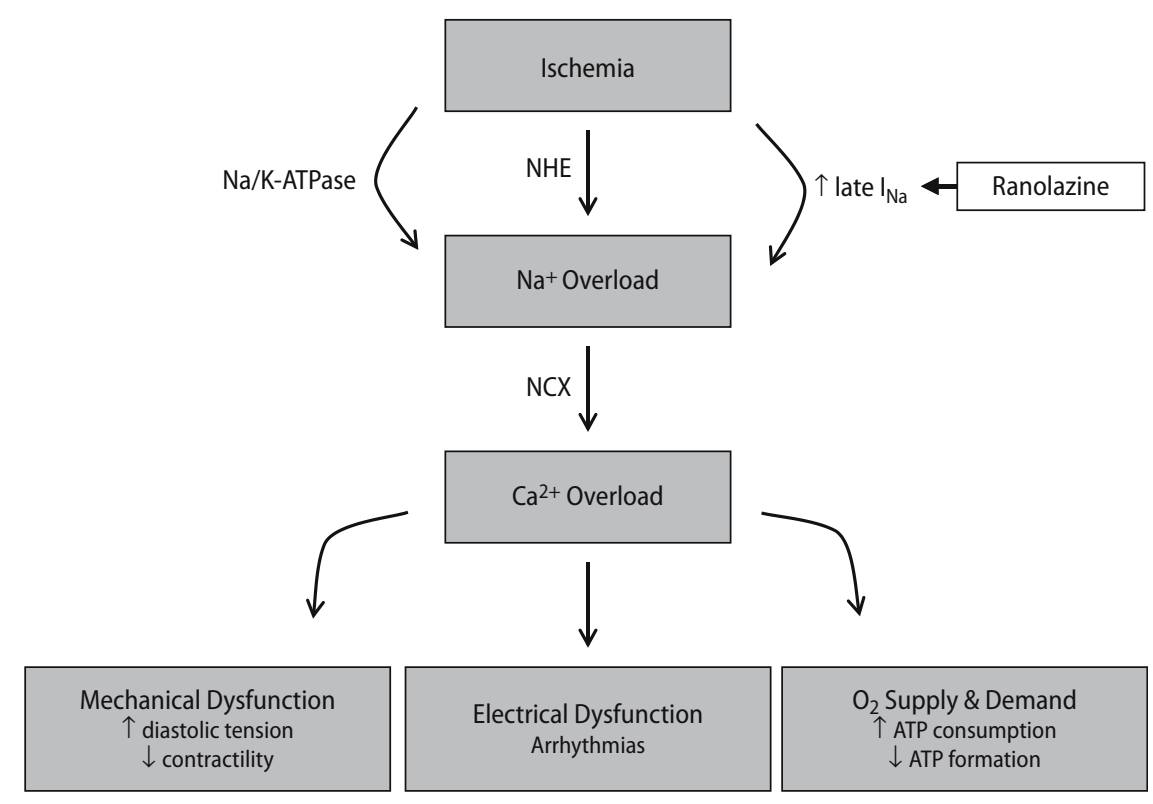

addition may improve blood flow and thus oxygen supply to the heart.

Ranolazine (Fig. 1), a piperazine derivative, is a new anti-ischemic drug for the treatment of angina, whose mode of action is different from the pharmacological principals mentioned above [3].

\section{Pathophysiology of myocardial ischemia relevant to the action of ranolazine}

Myocardial ischemia immediately results in reduced ATP fluxes and reduced energy supply to various key proteins for the contraction-relaxation cycle of the individual cardiac myocyte. These include proteins which control myocyte ion homeostasis. As a consequence, intracellular sodium, and calcium concentration are disturbed, which is relevant to myocardial damage following ischemia.

There are several mechanisms by which energy lack increases intracellular sodium (Fig. 2). A large portion of the sodium enters the cell through the cardiac sodium channel following depolarisation during the initial phase (fast upstroke) of the action potential. This sodium influx causes further rapid

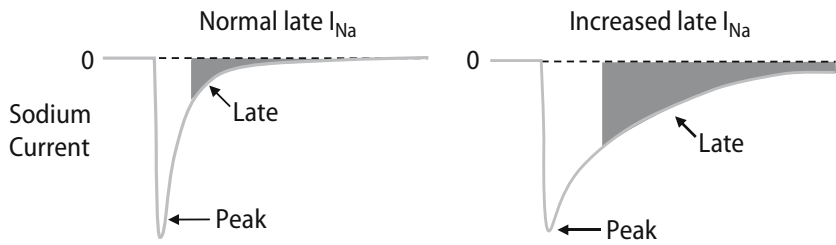

Fig. 3 Late $I_{\mathrm{Na}}$ under normal and increased late $I_{\mathrm{Na}}$ under pathophysiological conditions depolarisation leading to the activation of voltagegated L-type calcium channels causing calcium influx. Sodium channels spontaneously inactivate quickly within one to three milliseconds. Channels recycle and may be activated by the next membrane depolarisation $[8,22]$. It has been shown that this typical fast sodium current may be altered during pathological conditions such as hypoxia, exposure to ischemic metabolites and reactive oxygen species. Under those conditions, there is a pronounced late opening of the sodium channel up to a few hundreds of milliseconds following depolarisation referred to as late (or persistent) sodium current (late $\mathrm{I}_{\mathrm{Na}}$, Fig. 3) $[14,28,30$, 31]. Late $I_{\mathrm{Na}}$ may represent a major source for increased intracellular sodium during ischemia. Other mechanisms leading to disturbed sodium balance include sodium influx through the sodium-proton pump [7] or lack of sodium elimination through the sodium potassium ATPase.

Energy lack and the resulting decrease in the phosphorylation potential reduce free energy available for calcium transport into the sarcoplasmic reticulum and therefore intracellular calcium accumulates in the cytosol. As a consequence, elevated diastolic calcium levels activate contractile proteins even during diastole leading to diastolic dysfunction. Disturbed sarcoplasmic reticulum calcium accumulation is severely aggravated by elevated intracellular sodium. This mainly occurs through the sarcolemmal sodium-calcium exchanger, which exchanges one calcium ion for three sodium ions per cycle. The sodium-calcium exchanger can work in two different directions. In its forward mode, it eliminates calcium outside of the cell to accomplish diastolic relaxation (in addition to calcium reuptake into the sarcoplasmic reticulum). In its 
reverse mode (usually during the action potential), it brings in calcium into the cell in exchange to transsarcolemmal elimination of sodium. The activity and direction of transport depends on the abundance of the protein as well as on the membrane potential, intracellular sodium and intracellular calcium concentration. Sodium accumulation following myocardial hypoxia (i.e., through late $\mathrm{I}_{\mathrm{Na}}$ ) promotes reverse mode sodium-calcium exchange and therefore reduces the overall cellular capacity to eliminate calcium outside of the cytosol. This adds to the elevated diastolic calcium due to reduced sarcoplasmic reticulum calcium pump activity and further aggravates diastolic dysfunction due to contractile protein activation. Diastolic activation of contractile proteins is associated with extra energy consumption [17]. Moreover, increased diastolic tone increases micro-circulatory resistance and further impairs energy balance of the ischemic myocardium. Therefore, diastolic dysfunction following myocardial ischemia increases energy consumption and aggravates disturbed energy balance like a vicious cycle.

Ranolazine has been shown to be a potent inhibitor of late $\mathrm{I}_{\mathrm{Na}}$ and therefore interrupts a major step in the pathophysiology of myocardial ischemia [1].

\section{Mode of action of ranolazine}

In myocytes from dog and guinea pig hearts, ranolazine was shown to cause a concentration, voltage, and frequency-dependent inhibition of late $\mathrm{I}_{\mathrm{Na}}$ [1]. Ranolazine also was shown to prevent $\mathrm{H}_{2} \mathrm{O}_{2}$ induced increase in late $\mathrm{I}_{\mathrm{Na}}$ [25]. Most specifically, ranolazine has been shown to reverse the sustained rise in diastolic and systolic calcium caused by a well-known enhancer of late $\mathrm{I}_{\mathrm{Na}}$, the sea anemone toxin ATX-II $[10,26]$. Taken together, the major mechanism of action of ranolazine is to inhibit late $\mathrm{I}_{\mathrm{Na}}$ thus preventing sodium overload of the cell. As a consequence, ranolazine prevents reverse mode sodiumcalcium exchange and thus diastolic accumulation of calcium possibly resulting in improved diastolic tone $[12,27]$ and improved coronary blood flow [10]. Accordingly, ranolazine has been shown to decrease post-ischemic contracture in rabbit isolated perfused hearts subjected to ischemia and reperfusion [11].

As a late $\mathrm{I}_{\mathrm{Na}}$ inhibitor, ranolazine was also shown to increase action potential duration and thus modestly QT interval by 2-5 ms $[5,6]$. This effect, however, is not heart rate-dependent and cannot be exaggerated during bradycardia $[2,19,32]$. Furthermore, ranolazine does not induce early after depolarisations and does not increase dispersion of repolarisation across the left ventricular wall [2]. According to this profile ranolazine does not increase the risk of Torsade de pointes tachycardia as it is observed with many other QT interval prolonging agents.

\section{Clinical effects of ranolazine}

Ranolazine has yet been studied in several clinical trials. Three initial trials have investigated the efficacy of immediate release ranolazine $[9,20,23]$. Two larger phase three studies have examined the efficacy of sustained release ranolazine in patients with chronic stable angina. MARISA (Monotherapy Assessment of Ranolazine In Stable Angina) randomised 191 patients to placebo or ranolazine in a cross-over design with 1 week treatment period [6]. CARISA (Combination Assessment of Ranolazine in Stable Angina) randomised patients to placebo or ranolazine on top of previous anti-anginal therapy. Treatment was maintained for 12 weeks [5]. MARISA showed that ranolazine monotherapy significantly improved exercise performance in patients with stable angina. This was true for exercise duration, time to angina and time to $1 \mathrm{~mm} \mathrm{ST}$ segment depression. More specifically, $70 \%$ of patients in the placebo group stopped their exercise test because of angina as compared to only $52 \%$ in the ranolazine group ( $1.5 \mathrm{~g}$ bidaily). CARISA improved peak and trough exercise duration, time to angina and time to $1 \mathrm{~mm}$ ST depression. These effects were sustained through a 12-week treatment. Also, ranolazine reduced the number of angina attacks from a baseline of 4.5 per week to 2.1 per week for ranolazine ( $1 \mathrm{~g}$ bidaily) compared to 3.3 per week for placebo. Most importantly, the anti-anginal effects of ranolazine in MARISA and CARISA occurred without clinical meaningful changes in heart rate or blood pressure.

In the MERLIN (Metabolic Efficiency with Ranolazine for Less Ischemia in Non-ST elevation acute coronary syndrome) TIMI-36 trial, the effect of clinical outcome of ranolazine therapy was studied in patients with acute coronary syndromes [18]. MERLIN was a multi-national, double-blind, randomised, placebocontrolled, parallel-group clinical trial designed to evaluate the efficacy and safety of ranolazine during acute and long-term treatment in 6560 patients with non-ST elevation ACS treated with standard therapy. Within $48 \mathrm{~h}$ of the onset of angina due to ACS, eligible hospitalised patients were enrolled in the study and randomised to receive intravenous ranolazine or placebo, followed by long-term treatment with ranolazine tablets or placebo. Although ranolazine did not significantly influence the primary combined endpoint of cardiovascular death, myocardial infarction or recurrent ischemia, additional analyses revealed a $13 \%$ relative reduction in the risk of recurrent ischemia. Furthermore, ranolazine was favourable regarding 
safety endpoints. In particular potential antiarrhythmic effects of ranolzine became apparent [24]. This underlines experimental data [4]. Thus inhibition of late $\mathrm{I}_{\mathrm{Na}}$ with ranolazine is safe in particular regarding electrophysiological aspects. Although the results of MERLIN do not support the use of ranolazine for acute management of ACS these findings support previous finding regarding safety and benefit of ranolazine as an antianginal therapy and suggest a benefit of ranolazine as antianginal therapy in a broad population of patients with established ischemic heart disease.

\section{Future aspects for clinical application for ranolazine}

Inhibition of enhanced late $\mathrm{I}_{\mathrm{Na}}$ by ranolazine may represent a new treatment option for cardiac diseases associated with disturbed myocardial ion homeostasis. Elevated intracellular sodium has been observed in human heart failure and in several animal failure models $[15,21]$. It has been shown recently that in- creased intracellular sodium in heart failure may, in part, result from CaMKII-dependent phosphorylation of sodium channels with subsequent increase in late $\mathrm{I}_{\mathrm{Na}}$ [29]. Therefore, ranolazine may be an interesting approach for the treatment of systolic heart failure by improving disturbed sodium homeostasis. Moreover, calcium overload subsequent to disturbed sodium homeostasis may also be a major pathophysiological factor in diastolic heart failure. Therefore we speculate that in diastolic heart failure due to disturbed sodium/calcium homeostasis, ranolazine may represent a new attractive treatment option. Accordingly, studies in heart failure with systolic and diastolic dysfunction are warranted to test the potential therapeutical benefit of ranolazine.

Acknowledgements G.H. and L.S.M. are funded by the Deutsche Forschungsgemeinschaft (DFG) through grants for a Clinical Research group (MA 1982/2-1), L.S.M. in addition by a DFG Emmy Noether-grant (MA 1982/1-5). Conflict of interest: All authors have a collaboration/grant with CV Therapeutics.

\section{References}

1. Antzelevitch C, Belardinelli L, Zygmunt AC et al (2004) Electrophysiological effects of ranolazine, a novel antianginal agent with antiarrhythmic properties. Circulation 110:904-910

2. Antzelevitch C, Belardinelli L, Zygmunt AC et al (2004) Electrophysiological effects of ranolazine, a novel antianginal agent with antiarrhythmic properties. Circulation 110:904-910

3. Belardinelli L, Antzelevitch C, Fraser $\mathrm{H}$ (2004) Inhibition of late (sustained/ persistent) sodium current: a potential drug target to reduce intracellular sodium-dependent calcium overload and its detrimental effects on cardiomyocyte function. Europ Heart J 6(Suppl I):13-17

4. Burashnikov A, Di Diego JM, Zygmunt AC, Belardinelli L, Antzelevitch C (2007) Atrium-selective sodium channel block as a strategy for suppression of atrial fibrillation: differences in sodium channel inactivation between atria and ventricles and the role of ranolazine. Circulation. 116:1449-1457

5. Chaitman BR, Pepine CJ, Parker JO et al (2004) Effects of ranolazine with atenolol, alodipine, or diltiazem on exercise tolerance and angina frequency in patients with severe chronic angina: a randomized controlled trial. J Am Med Assoc 291:309-316
6. Chaitman BR, Skettino SL, Parker JO et al (2004) Anti-ischemic effects and long-term survivial during ranolazine monotherapy in patients with chronic severe angina. J Am Coll Cardiol 43:1375-1382

7. Clanachan AS (2004) Assessment of Ranolazine's Effects on Mechanical Function and $\left[\mathrm{Ca}^{2+}\right]_{\mathrm{i}}$ Accumulation in Ejecting Rat Hearts (CVT Technical Report Number CVT303.093-P)

8. Clancy CE, Kass RS (2002) Defective cardiac ion channels: from mutations to clinical syndromes. J Clin Invest 110:1075-1077

9. Cocco G, Rousseau MF, Bouvy T et al (1992) Effects of a new mebatolic modulator, ranolazine on exercise tolerance in angina pectoris patients treated with beta-blocker or diltiazem. J Cardiovasc Pharmacol 20:131-138

10. Fraser H, Belardinelli L, Wang L, Light PE, McVeigh JJ, Clanachan ASD (2006) Ranolazine decreases diastolic calcium accumulation caused by ATX-II or ischemia in rat hearts. J Mol Cell Cardiol 41:1031-1038

11. Gralinski MR, Black SC, Kilgore KS et al (1994) Cardioprotective effects of ranolazine (RS-43285) in the isolated perfused rabbit heart. Cardiovasc Res 28:1231-1237
12. Hayashida W, van Eyll C, Rousseau MF, Pouleur H (1994) Effects of ranolazine on left ventricular regional diastolic function in patients with ischemic heart disease. Cardiovasc Drugs Ther 8:741-747

13. Heusch G, Schulz R (2001) Perfusioncontraction match and mismatch. Basic Res Cardiol 96:1-10

14. Ju YK, Saint DA, Gage PW. (1996) Hypoxia increases persistent sodium current in rat ventricular myocytes. J Physiol 497(Pt2):337-347

15. Maier LS, Hasenfuss G (2006) Role of $\left[\mathrm{Na}^{+}\right]_{\mathrm{i}}$ and the emerging involvement of the late $\mathrm{Na}$ current $\left(\mathrm{I}_{\mathrm{Na} \text {,late }}\right)$ in the pathophysiology of cardiovascular disease. Europ Heart J 8(Suppl A):A6-A9

16. Messerli FH, Mancia G, Conti CR, Pepine CJ (2006) Eur Heart J 27(23):29022903

17. Meyer M, Keweloh B, Guth K, Holmes JW, Pieske B, Lehnart SE, Just H, Hasenfuss G (1998) Frequency-dependence of myocardial energetics in failing human myocardium as quantified by a new method for the measurement of oxygen consumption in muscle strip preparations. J Mol Cell Cardiol 30(8):1459-1470 
18. Morrow DA, Scirica BM, Karwatoswska-Prokopczuk E, Murphy SA, Budaj A, Varshavsky S, Wolff A, Skene A, McCabes CH, Braunwald E (2007) Effects of Ranolazine on recurrent cardiovascular events in patients with non-ST-elevation acute coronary syndromes. The MERLIN-TIMI 36 Randomized Trial. JAMA 297(16):17751783

19. Okada Y, Ogawa S, Sadanaga $\mathrm{T}$ et al (1996) Assessment of reverse usedependent blocking actions of class III antiarrhythmic drugs by 24-h Holter electrocardiography. J Am Coll Cardiol 27:84-89

20. Pepine CJ, Wolff AA (1999) A controlled trial with a novel anti-ischemic agent, ranolazine, in chronic stable angina pectoris that is responsive to conventional antianginal agents. Am J Cardiol 84:46-50

21. Pieske B, Maier LS, Piacentino V III, Weisser J, Hasenfuss G, Houser S (2002) Rate dependence of $\left[\mathrm{Na}^{+}\right]_{\mathrm{i}}$ and contractility in nonfailing and failing human myocardium. Circulation 106:447-453

22. Roden DM (2001) Cardiac membrane and action potentials. In: Spooner PM, Rosen MR et al. (eds) foundations of cardiac arrhythmias: basic concepts and clinical approaches. Marcel Dekker, New York, p. 21
23. Rousseau MF, Visser FG, Bax JJ (1994) Ranolazine: antianginal therapy with a novel mechanism: placebor controlled comparison versus atenolol. Eur Heart J 15(Suppl):95

24. Scirica BM, Morrow DA, Hod H, Murphy SA, Belardinelli L, Hedgepeth CM, Molhoek P, Verheugt FW, Gersh BJ, McCabe CH, Braunwald E (2007) Effect of Ranolazine, an Antianginal Agent With Novel Electrophysiological Properties, on the Incidence of Arrhythmias in Patients With Non ST-Segment Elevation Acute Coronary Syndrome: Results From the Metabolic Efficiency With Ranolazine for Less Ischemia in Non ST-Elevation Acute Coronary Syndrome Thrombolysis in Myocardial Infarction 36 (MERLIN-TIMI 36) Randomized Controlled Trial. Circulation 116(15):1647-1652

25. Song Y, Shryock JC, Wagner S, Maier LS, Belardinelli L (2006) Blocking late sodium current reduces hydrogen peroxide-induced arrhythmogenic activity and contractile dysfunction. J Pharmacol Exp Ther 318:214-222

26. Song Y, Shryock JC, Wu L et al (2004) Antagonism by ranolazine of the proarrhythmic effects of increasing late INa in guinea pig ventricular myocytes. J Cardiovasc Pharmacol 44:192-199
27. Sossalla S, Rasenack ECL, Wagner S, Ruff H, Tenderich G, Hasenfuss G, Belardinelli L, Maier LS (2007) Inhibition of late sodium current by ranolazine improves diastolic dysfunction in human heart failure. $\mathrm{Z}$ Kardiol 96(Suppl 1):P837

28. Undrovians AI, Fleidervish IA, Makielski JC (1992) Inward sodium current at resting potentials in single cardiac myocytes induced by the ischemic metabolite lysophosphatidylcholine. Circ Res 71:1231-1241

29. Wagner S, Dybkova N, Rasenack ECL, Jacobshagen C, Fabritz L, Kirchhof P, Maier SKG, Zhang T, Hasenfuss G, Heller Brown J, Bers DM, Maier LS (2006) $\mathrm{Ca} / \mathrm{calmodulin}$-dependent protein kinase II regulates cardiac $\mathrm{Na}$ channels. J Clin Invest. 116:3127-3138

30. Ward CA, Giles WR.(1997) Ionic mechanism of the effects of hydrogen peroxide in rat ventricular myocytes. J Physiol 500(Pt 3):631-642

31. Wu J, Corr PB. (1994) Palmitoyl caritine modifies sodium currents and induces transient inward current in ventricular myocytes. Am J Physiol 266:H1034-H1046

32. Wu L, Shryock JC, Song Y et al (2004) Antiarrhythmic effects of ranolazine in a guinea pig in vitro model of long-QT syndrome. J Pharmacol Exp Ther 310:599-605 